\title{
From where did the 2009 'swine-origin' influenza A virus
} (HINI) emerge?

\author{
Adrian J Gibbs*1, John S Armstrong ${ }^{1}$ and Jean C Downie ${ }^{2}$
}

Address: ${ }^{1}$ Australian National University Emeritus Faculty, ACT, 0200, Australia and ${ }^{2}$ CIDMLS, ICPMR, Westmead Hospital, NSW, 2145, Australia

Email: Adrian J Gibbs* - adrian_j_gibbs@hotmail.com; John S Armstrong - j_s_armstrong@hotmail.com;

Jean C Downie - jean.downie@bigpond.com.au

* Corresponding author

Published: 24 November 2009

Virology Journal 2009, 6:207 doi:10.1 186/1743-422X-6-207

This article is available from: http://www.virologyj.com/content/6/1/207

(C) 2009 Gibbs et al; licensee BioMed Central Ltd.

This is an Open Access article distributed under the terms of the Creative Commons Attribution License (http://creativecommons.org/licenses/by/2.0), which permits unrestricted use, distribution, and reproduction in any medium, provided the original work is properly cited.
Received: 29 July 2009

Accepted: 24 November 2009

\begin{abstract}
The swine-origin influenza $\mathrm{A}$ (HINI) virus that appeared in 2009 and was first found in human beings in Mexico, is a reassortant with at least three parents. Six of the genes are closest in sequence to those of HIN2 'triple-reassortant' influenza viruses isolated from pigs in North America around 1999-2000. Its other two genes are from different Eurasian 'avian-like' viruses of pigs; the NA gene is closest to HINI viruses isolated in Europe in 1991-1993, and the MP gene is closest to H3N2 viruses isolated in Asia in 1999-2000. The sequences of these genes do not directly reveal the immediate source of the virus as the closest were from isolates collected more than a decade before the human pandemic started. The three parents of the virus may have been assembled in one place by natural means, such as by migrating birds, however the consistent link with pig viruses suggests that human activity was involved. We discuss a published suggestion that unsampled pig herds, the intercontinental live pig trade, together with porous quarantine barriers, generated the reassortant. We contrast that suggestion with the possibility that laboratory errors involving the sharing of virus isolates and cultured cells, or perhaps vaccine production, may have been involved. Gene sequences from isolates that bridge the time and phylogenetic gap between the new virus and its parents will distinguish between these possibilities, and we suggest where they should be sought. It is important that the source of the new virus be found if we wish to avoid future pandemics rather than just trying to minimize the consequences after they have emerged. Influenza virus is a very significant zoonotic pathogen. Public confidence in influenza research, and the agribusinesses that are based on influenza's many hosts, has been eroded by several recent events involving the virus. Measures that might restore confidence include establishing a unified international administrative framework coordinating surveillance, research and commercial work with this virus, and maintaining a registry of all influenza isolates.
\end{abstract}

\section{Introduction}

A novel H1N1 influenza virus, Swine-Origin Influenza Virus (S-OIV), was first isolated in mid-April 2009 and, by the end of the month, the first complete genomic sequences were published, and the virus shown to be of a novel re-assortant [1]. The virus spread fast in the human population, and the resulting pandemic has already proved to be a significant and very costly cause of mortality and morbidity in the human population. It has created intense interest worldwide. Several hundred research papers, reports, reviews and summaries [2,3] have been published about this virus in the last six months. Many 
discuss its genealogy deduced from its gene sequences, however it seems that we have no clearer evidence of its immediate origins than we have of the influenzas that caused past influenza pandemics. So the search for its source must be intensified while the clues are still fresh. The possibility that human activity may have had some role in its origins should not be dismissed without a dispassionate analysis of all available evidence. If we wish to avoid future pandemics, rather than just minimizing the damage they cause, we must better understand what conditions produce them.

Several phylogenetic studies of the gene sequences of SOIV and other influenzas have now been reported [4-10]. In these studies the sequences have been compared using various techniques (e.g. statistical inference (SI), neighbour-joining, maximum parsimony and principal components analyses), and have involved various selections of the very large number of influenza gene sequences that are now publicly available. Most phylogenetic studies compared nucleotide sequences, and at least one compared the encoded amino acid sequences.

All studies have concluded that S-OIV emerged into the human population on a single occasion, probably around January $2009[8,11]$. They agree that six of its genes, those encoding the polymerase proteins (PB2, PB1 and PA), the haemagglutinin (HA), the nucleoprotein (NP) and the non-structural proteins (NS), show a clear affinity with those of the 'triple-reassortant' influenza viruses first found in North American pigs around 1998, whereas the other two genes, those encoding the neuraminidase (NA) and matrix proteins (MP), are from the Eurasian 'avianlike' virus lineage first isolated in Europe around 1979 [12-19]. Neither the 'triple- reassortant' viruses nor their individual genes have previously been found in Europe nor, likewise, have those of the 'avian-like' lineage been found in North America. However, viruses of both lineages have been found more recently in South East Asia $[20,21]$, but reasortants intermediate between S-OIV and its parental lineages have not [22].

\section{Discussion \\ Phylogenetic Studies}

One of the most intriguing findings of the phylogenetic studies is that each S-OIV gene is connected to its respective phylogenetic tree by a noticeably long branch. This indicates that, immediately before its emergence, each had a period of "unsampled ancestry", which Smith and his colleagues estimated to be between 9.2 and 17.2 years long for the different genes [8]. Garten and her colleagues concluded however that "Though long, these branch lengths are not unusual for swine viruses; there are 52 other similar or longer branch lengths in the swine phylogenetic trees" that they published. However, Garten and her colleagues compared viruses collected over nine decades under a wide range of sampling intensities. It would be more appropriate to compare phylogenetically close isolates collected around the same time. We looked at branch lengths in a maximum likelihood tree of $160 \mathrm{HA}$ nucleotide sequences most closely related to those of SOIV, and found that after the long branch to the S-OIV HA gene cluster, the next longest branch was 79 isolates away and the next a further 21. There is a clear contrast between the branch lengths in trees of diverse sequences, and those in sister and cousin lineages.

Another unusual feature of the long S-OIV branches [8] is that the lengths and error ranges of the branches of seven of the genes estimated by Smith and colleagues (Table 1 in [8]) form a single broadly overlapping cluster (Fig. 1) with a mean length of $11.02+/-1.05$ years, whereas those of the NA gene are significantly longer and indicate that it had not been sampled for more than $17.15+/-1.74$ years. Thus although the NA and MP genes of S-OIV were both from the Eurasian avian-like lineage of influenza viruses, they probably first became associated with the S-OIV lineage on separate occasions, and hence came from two different viruses. We conclude therefore that S-OIV probably had at least three immediate parents, not two.

The reports of the phylogenetic studies disagree most obviously in the sequences found to be closest to those of S-OIV. This is not surprising because the studies analysed different sets of sequences selected in different ways and different analytical techniques were used. Furthermore, the statistical inference methods used by some may not be ideal for identifying close neighbours in large datasets; evolution is stochastic, and close relationships are not statistical, and so a tree fitted statistically to a very large number of sequences [8] probably confounds close phylogenetic relationships, especially when those relationships have been globally optimized [7]. We therefore checked whether more consistent information about SOIV's immediate parental lineages could be obtained from its gene sequences by using a more selective and direct approach. We first used SWeBLAST [23], a variant of BLAST, to select from the Genbank database only the sequences closest to those of S-OIV, then inferred their relationships using a maximum likelihood method, and finally ranked the sequences by their patristic distances within the trees using PATRISTIC [24].

Our analyses showed that almost all the closest genes came from pig isolates. The NA genes closest to the 04/ 2009 NA were all from 'avian-like' H1N1 isolates from Europe sampled around 1991 (Figure 2) and Additional file 1; closest were A/swine/Spain/WVL6/1991 (H1N1) (0.0706 nucleotide substitutions/site: ns/s), A/swine/England/WVL7/1992 (H1N1) (0.0718ns/s) and A/swine/ 


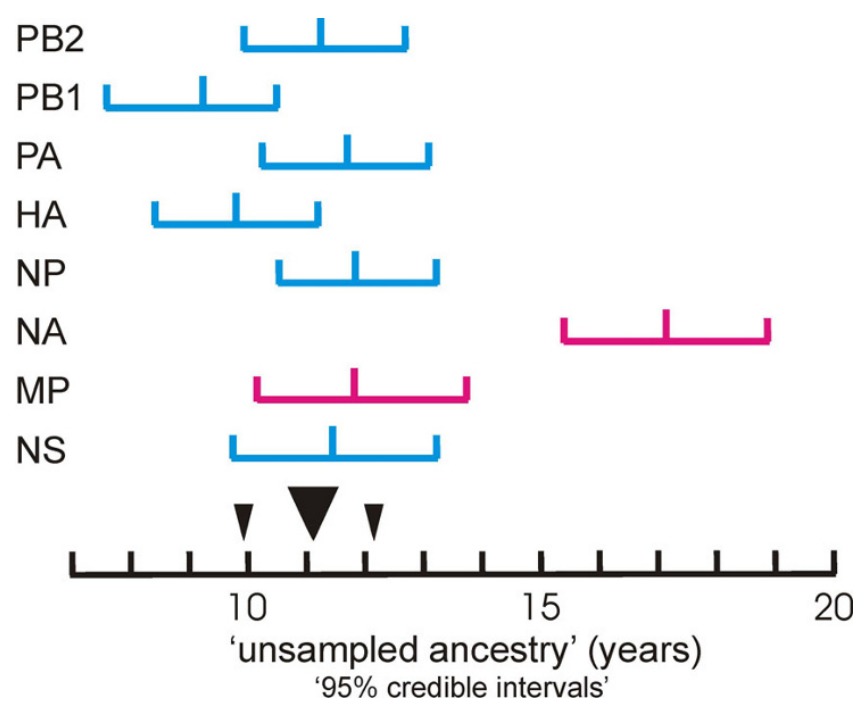

Figure I

Graph showing the duration of the "unsampled ancestry of different S-OIV genes. The data is from Table I of [8], and the error bars give the "95\% credible intervals". The data from the lineage of the triple reassortant parent are in blue, those from the Eurasian 'avian-like' swine virus lineage in red. The black triangles indicate the mean and standard deviation of the values for the triple reassortant and MP lineage genes combined.

England/WVL10/1993 (H1N1) (0.0753ns/s). The MP genes closest to the 04/2009 MP gene were also from 'avian-like' isolates but collected in Asia around 1999 (Figure 3); closest were A/swine/Hong Kong/5200/1999 (H3N2), A/swine/Hong Kong/51901999 (H3N2) and A/ swine/Hong Kong/5212/1999 (H3N2) (all 0.0254 ns/s). The other six genes, including the HA gene (Figure 4), were closest to those of North American 'triple-reassortant' isolates sampled around or soon after 1999; most were H1N2 isolates from pigs, although a few of the polymerase genes were close to H3N2 isolates (data not shown). We narrowed the search for the triple reassortant parent by assuming, as is likely, that the six S-OIV genes came from a single triple reassortant rather than two or more. We found that there were five triple-reassortant isolates with four or five genes that were among the twenty closest to those of 04/2009 (Table 1). Closest of all were A/swine/Indiana/9K035/1999 (H1N2), A/swine/Indiana/ $\mathrm{P} 12439 / 2000$ (H1N2) and A/swine/Minnesota/55551/ 2000 (H1N2).

So, in summary, our analyses provide consistent evidence that the immediate parents were swine viruses. The sampling dates of those isolates are congruent with the estimated lengths of 'unsampled ancestry' of the parents [8] and, together with differences in provenance support the conclusion that S-OIV had three parents; one from North America, one from Europe and the third from Asia.

\section{Hypotheses}

The results of the phylogenetic analyses outlined above can be used to construct plausible scenarios of the ways in which S-OIV might have originated. This is a useful exercise as it may focus the search for new clues. Some of the crucial evidence provided by the phylogenetic analyses is that:

1) S-OIV emerged into the human population on a single occasion, probably in Mexico.

2) S-OIV is a reassortant with at least three parental viruses, all of them viruses of pigs.

3) the parents of S-OIV were last sampled directly in three very distant parts of the world.

4) the parental genes were last sampled more than a decade ago. Two were sampled around 11 years ago, the third 17 years ago, whereas their sister and cousin lineages have been sampled frequently.

S-OIV could have been generated by natural means. The parental isolates could, for example, have been assembled in one place by migratory birds, however the consistent link of S-OIV's immediate ancestors with pigs suggests that human activity of some sort was involved in bringing together the parental viruses. At least two contrasting theories are congruent with this possibility and the available clues:

1) The "unsampled pig herd" theory was suggested by Smith and his colleagues [8], who concluded that "the progenitor of the S-OIV epidemic originated in pigs", and the "long unsampled history observed for every segment" of the S-OIV genome "suggests that the reassortment of Eurasian and North American swine lineages may not have occurred recently, and it is possible that this single reassortant lineage has been cryptically circulating rather than two distinct lineages of swine flu", and that "Movement of live pigs between Eurasia and North America seems to have facilitated the mixing of diverse swine influenzas, leading to the multiple reassortment events associated with the genesis of the S-OIV strain."

This theory was implicitly supported by Trifonov and his colleagues in their report of a study of the numbers of gene sequences deposited in Genbank from human and pig influenzas sampled around the world in different years [25]. They had found that, although the number of influenza sequences deposited had increased greatly in the last decade, there were four times as many human as pig influenza sequences. Furthermore, whereas the sequenced human isolates came from all over the world, the pig isolates came 
Table I: Distances between genes of A/California/04/2009 (HINI) and those of the closest HIN2 isolates.

\begin{tabular}{|c|c|c|c|c|c|c|}
\hline & PB2I & PBI & PA & HA & NP & NS $^{3}$ \\
\hline $\mathrm{A} /$ swine/Indiana/PI2439/2000 & $0.0368 * 2$ & 0.0430 & 0.0474 & 0.0525 & $0.0360 *$ & 0.0533 \\
\hline A/swine/Indiana/9K035/I999 & 0.0406 & $0.0395 *$ & 0.0498 & $0.0513^{*}$ & 0.0387 & 0.0439 \\
\hline $\mathrm{A} /$ swine/Minnesota/5555I/2000 & 0.0372 & 0.0451 & $0.0450 *$ & 0.1224 & 0.0408 & $0.0427^{*}$ \\
\hline $\mathrm{A} /$ swine/lllinois//00084/200I & 0.0446 & 0.0434 & 0.0451 & 0.0597 & 0.0404 & 0.0528 \\
\hline $\mathrm{A} /$ swine/lllinois/I00085A/200I & 0.0453 & 0.0420 & 0.0486 & 0.0578 & 0.0404 & 0.0539 \\
\hline
\end{tabular}

I Genes: PB2, PBI and PA, polymerase genes; HA, haemagglutinin; NP, nucleoprotein; NS, non-structural proteins I and 2

2 Patristic distances; nucleotide substitutions/site. The isolate that gave the shortest distance for each gene is marked with an asterisk.

${ }^{3}$ All five NSI genes encode a slightly truncated (219 amino acids) NSI protein as does the NSI gene of S-OIV.

only from North America, Asia, and Europe, and none from Africa, Oceania, or South America. They concluded that, given "the lack of sampling" of pigs "in certain parts of the world, it is perhaps not surprising that the ancestors of the new human influenza A (H1N1) virus have gone unnoticed for almost two decades." [26].

It is important to note that this theory depends on the intercontinental movement of live infected pigs, and requires at least two quarantine-breaching incursions involving three different countries. It is likely that quarantine control of the spread of swine influenzas around the world varies greatly in its efficacy. However viruses of the Eurasian 'avian-like' lineage, and their genes, have never been found in North America before S-OIV appeared, even though they have been common in Europe for over three decades, and similarly 'triple reassortant' viruses and their genes have not been isolated in Europe, although they have been the dominant swine influenza virus in North America for more than a decade.

2) The "laboratory error" theory. We note that influenza viruses survive well in virus laboratories, that laboratories are not subject to routine surveillance, and that there are probably many laboratories in the world that share and propagate a range of swine influenza viruses from different sources and continents, and also share and use immortalized lines of cultured cells. The viruses are used for research, diagnostic tests and for making vaccines, and the cells are used for propagating the viruses. Thus if S-OIV had been generated by laboratory activity, when one host was simultaneously infected with strains from the different parental lineages, this would explain most simply why S-OIV's genes had escaped surveillance for over a decade, and how viruses last sampled in North America, Europe and Asia became assembled in one place and generated a reassortant.

So what sort of laboratory event might produce mixed infections with different strains of influenza, and thereby generate S-OIV? The simplest is that S-OIV is a reassortant produced during research. There is also the possibility that it was generated during the production of multivalent vaccines. Multivalent 'killed' vaccines are mixtures of virions that have been grown in hen's eggs and then chemically sterilized. Thus a reassortant might be produced if insufficient sterilant, usually formaldehyde or propiolactone, is added to the virion mixture. The live mixture could then infect pigs 'vaccinated' with it, and the growing viruses could reassort, infect piggery staff and hence spread to the broader human population. Finally, it is possible that serially passaged cells, such as the Madin-Darby canine kidney (MDCK) cells now widely used in influenza laboratories, became latently and serially infected with different strains of influenza as a result of lax laboratory practices. This process could generate reassortants, and infect staff.

\section{Circumstantial Evidence}

There are clear historical precedents for most of the events described in the above scenarios. Viruses do 'escape' from laboratories, even high security facilities. The H1N1 influenza lineage that circulated in the human population for four decades after the 1918 Spanish influenza epidemic, disappeared during the 1957 Asian influenza pandemic, was absent for two decades, but then reappeared in 1977 . Gene sequences of the 1977 isolate and others collected in the 1950s were almost identical, indicating that the virus had not replicated and evolved in the interim, and had probably been held in a laboratory freezer between 1950 and 1977 and 'escaped' during passaging. The suggestion that persistently infected cells might be involved is also 


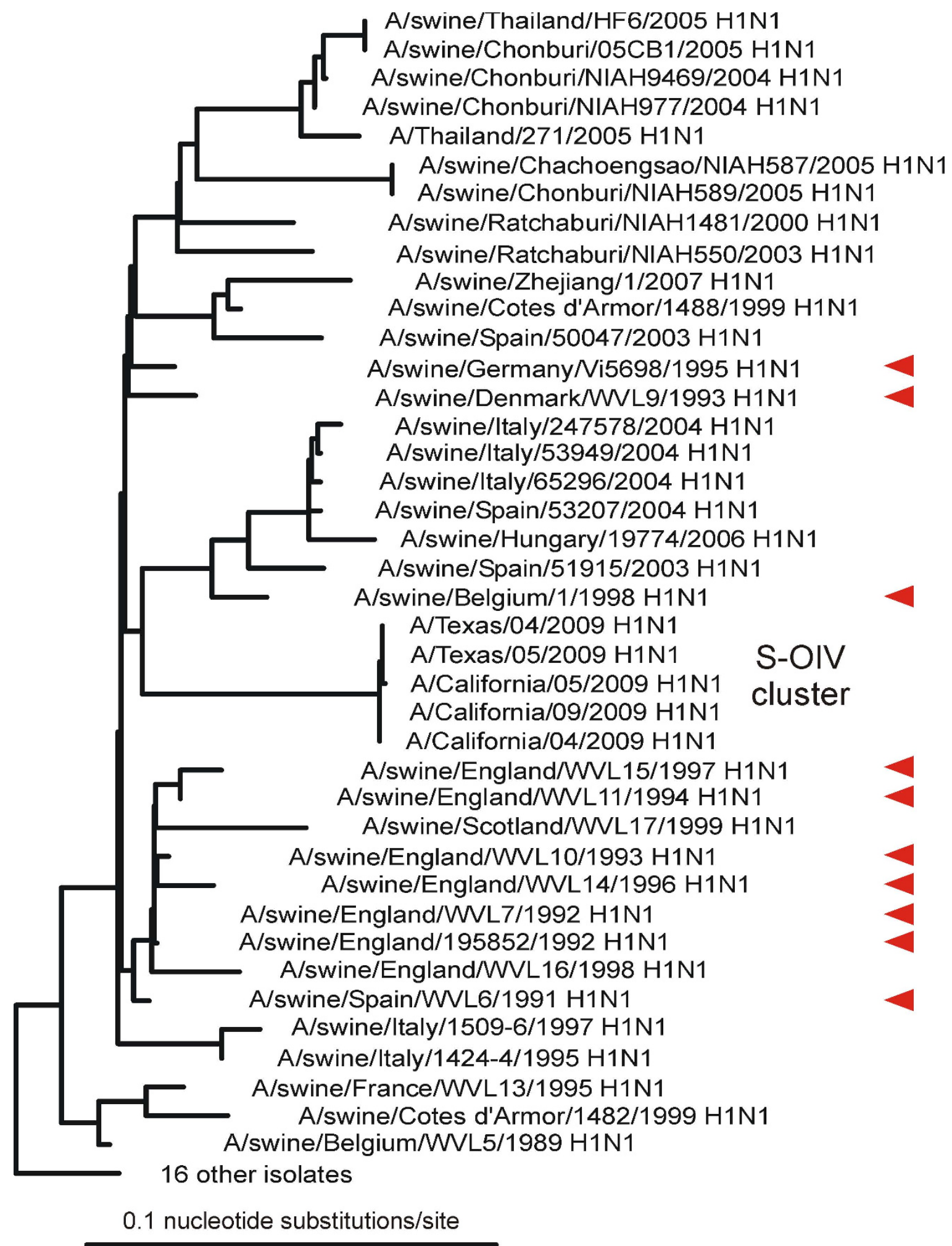

Figure 2

Unrooted maximum likelihood tree of the neuraminidase gene sequences of S-OIV and the most closely related sequences in Genbank. The ten closest are marked with red arrows. Details of the sequence selection and tree inference methods used are in Additional File I. 


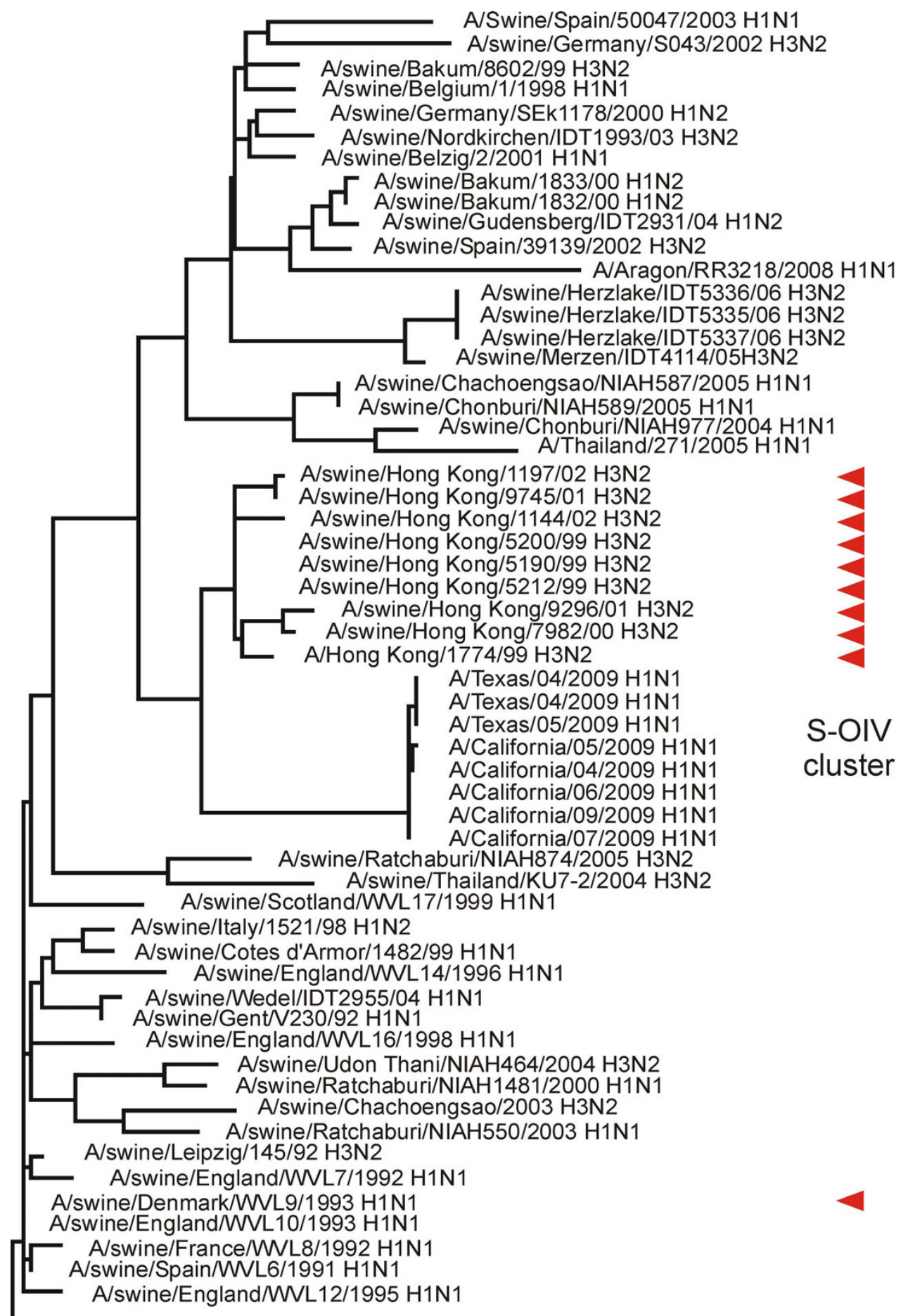

43 other isolates

0.05 nucleotide substitutions/site

Figure 3

Unrooted maximum likelihood tree of the gene sequences of the matrix proteins of S-OIV and the most closely related sequences in Genbank. The ten closest are marked with red arrows. Details of the sequence selection and tree inference methods used are in Additional File I. 


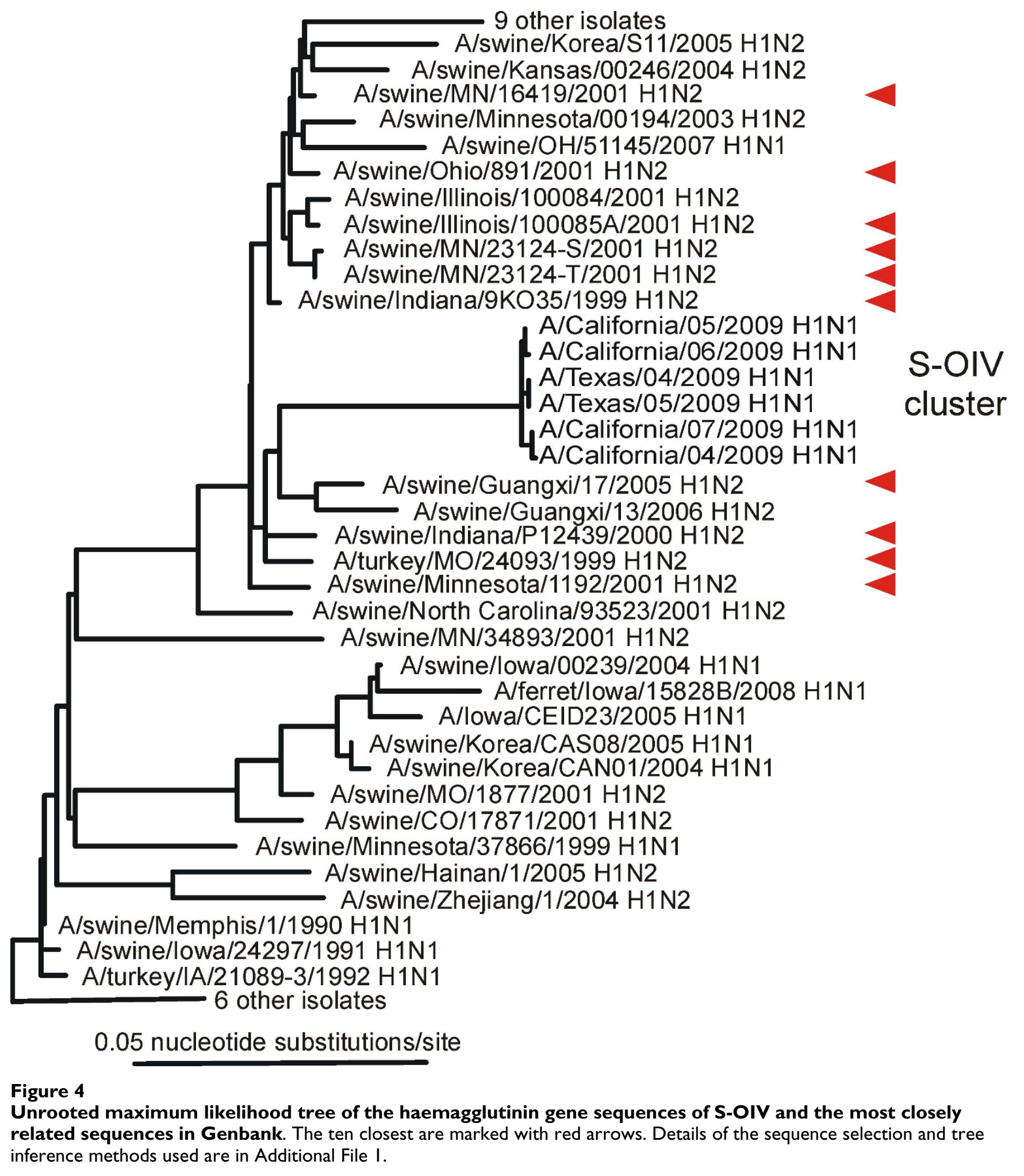


not outlandish; influenza virus can persistently and latently infect MDCK cells [27], and viruses do travel between laboratories in cells [28].

Multivalent 'killed' vaccines are widely used to control swine influenzas, particularly in North American piggeries [29], indeed one of the viruses identified by us and others (e.g. [30]) as closest to S-OIV, A/swine/Indiana/P12439/ 2000 (H1N2), seems to be the "2000 Indiana strain" used in commercial vaccines in North America [31]. We also note that isolates selected from the three clusters of viruses we find to be closest to S-OIV would probably make a useful trivalent vaccine for international use as they would provide a mixture of haemagglutinins of the swine $\mathrm{H} 3, \mathrm{H} 1$ 'classical swine' and H1 'Eurasian avian-like' lineages.

The patchy occurrence of S-OIV infections in piggeries over the past six months is interesting and may be significant. Pigs have been shown to be fully susceptible to SOIV. They shed the virus and readily transmit it between themselves, but whereas S-OIV has been reported in humans worldwide, it has not yet been reported from a pig farm in the USA (October 2009). By contrast it has been found in two piggeries each in Australia, Canada and Ireland, and one each in Argentina, Indonesia and Japan. In the outbreaks in Argentina, Australia and Canada, at least, the pigs had not been vaccinated (Jorge H. Dillon, J. Keenliside and Alain Laperle, personal communication), and became infected from infected farm staff. The apparent immunity to S-OIV of pigs in the USA and Mexico, but not elsewhere, may indicate that the swine influenza vaccines currently used in the USA and Mexico contain an immunogen that either protects against S-OIV infection or mitigates its symptoms.

Circumstantial evidence must always be treated with caution. One major uncertainty in trying to determine the origin of S-OIV is that one cannot predict which characters of the parental viruses have remained or changed during the reassortment process that produced S-OIV. If, for example, the significant infectiousness of S-OIV is an 'emergent' property of S-OIV, and not shown by its parents, then one could conclude that the final reassortment probably occurred at about the time it emerged in early 2009. However it is not yet known whether S-OIV's infectiousness is novel; the reassortment may have occurred a decade ago, and a recent mutation may have enhanced its infectiousness. Another widely reported feature of S-OIV is that it replicates poorly in embryonated eggs, but again this may be merely a specific feature of S-OIV and not its immediate parents. Similarly the fact that the evolutionary rate of all of the genes of S-OIV seem to be 'normal' during their unsampled pre-emergent period $[8,11]]$ does not prove that the virus or its parents have been maintained in "unsampled" pig herds and precluded the possi- bility of human involvement, as viruses grown for vaccines evolve, and indeed might be expected to show an increased evolutionary rate $[32,33]$ while adapting to eggs, a new host, although such an increase may have been offset by the practice of storing 'seed stocks' for use in several 'production cycles' in vaccine production, so that the evolutionary age of a vaccine virus may be less than its sidereal age, and the average could then appear to be 'normal'. Finally there is the report that the first human S-OIV infections were in Perote, a small Mexican town with a very large number of large piggeries, although it was also reported that none of the pigs showed signs of influenza. Among the earliest cases were some in Oaxaca, $290 \mathrm{kms}$ to the south [34]. Perote is an unlikely place for an infected migratory pig to arrive from an intercontinental trip, as the town is in a remote high valley surrounded by mountains, $200 \mathrm{kms}$ to the east of Mexico City where there is the nearest major airport, and $130 \mathrm{kms}$ from the nearest port at Vera Cruz. The four month difference between 'The Most Recent Common Ancestor' date for S-OIV estimated from its phylogeny $[8,11]$, and its earliest detection in the human population makes it more difficult to make specific conclusions about its provenance.

\section{Motifs and Sequence Signatures}

We have also checked whether any extra information about the origin of S-OIV can be gleaned from gene sequence features reported to be associated with host adaptation, virulence, etc. Such sequence signatures must be interpreted with caution as although Genbank records the source host of influenza isolates, it rarely records their passage hosts and passage history. Influenza viruses are nowadays mostly isolated in MDCK cells, but early influenza isolates were mostly grown in embryonated hen's eggs, and adaptation to eggs is known to cause protein sequence changes $[32,33,35,36]$. Therefore we compared sequence signatures and motifs in S-OIV with those of their closest relatives.

Subbarao and his colleagues [37] were first to show that amino acid 627 of the PB2 protein was almost always glutamate in bird isolates and lysine in human isolates. We checked 142 PB2 sequences, about one third each of isolates from birds, pigs and human beings, and found glutamate in contrast to lysine at this site in $98 \%$ and $70 \%$ of the bird and pig isolates. The only human isolates that had glutamate were all five S-OIVs, and three other human isolates; A/Hong Kong/156/1997(H5N1) and A/ Hong Kong/1073/1999(H9N2) both from human beings infected from birds, and A/Hong Kong/1774/ 1999(H3N2) which came from a person infected from pigs. Chen and colleagues [38] made a much more extensive survey of sequences and found 51 more sites in 10 of the 11 proteins of influenza virus that discriminated 
between bird and human isolates as well as, or better than, PB2-627. Unfortunately they did not report similarly specific sites for swine isolates, but we have checked whether any of those 52 sites (Table 1 in [38]) also distinguish S-OIV and its closest relatives, and found that only two of the 52 sites, PA-356 and NP-313, did. At 29 of the sites, the amino acids of the 'S-OIV cluster' (i.e. S-OIV and the swine viruses closest to it) are avian-like, at 16 they are human-like, at 6 (in the matrix proteins) they are novel, and the single recognised site in some NS1s has been lost by truncation. However, surprisingly, all the five recognised sites in the PB1-F2 protein of the S-OIV cluster have human-like residues, whereas the other 11 human-like residues are spread over 40 sites in eight proteins.

Another oddity of the S-OIV genome is that its PB1-F2 gene is truncated. In most influenza viruses the $\mathrm{PB} 1$ gene encodes three proteins $[39,40]$. The primary ORF encodes the PB1 and PB1-N40 proteins, and the PB1-F2 ORF, which encodes a proapoptotic protein of 90 amino acids, is in the second $(+1)$ reading frame of the gene starting at nt 95. In a small number of influenzas, including all SOIVs, the PB1-F2 ORF is truncated by termination codons at positions 12, 58 and 88 , and its absence is associated with avirulence in mice [41-43]. Trifonov and colleagues have reported statistical tests of various features of the PB1-F2 region [26], and concluded "that PB1-F2 is of little or no evolutionary significance for the virus".

We compared the PB1-F2 genes of S-OIV with those most closely related to them. Four of the five triple-reassortants closest to S-OIV (Table 1) have a complete PB1-F2, but one, A/swine/Minnesota/55551/2000, terminates at codon 58 and so is partly truncated. The PB1-F2 of another isolate, A/swine/Minnesota/3236/2007 (H1N2) has termination codons 12,26 and 58 and, together with A/swine/Ohio/75004/2004 (H1N1), which has termination codon 58, forms a distant sister group to the S-OIVs in a ML tree of the complete PB1 genes. A survey of the individual S-OIV PB1-F2 termination codons in 7644 PB1-F2 sequences (Genbank; August 2009) established that one might expect to find, at random, 0.46 sequences with all three termination codons in a dataset of that size, whereas they were found not only in S-OIV but also in the unrelated A/mallard/Alberta/300/1977 (H1N1) and A/ Siena/9/1989 (H1N1). The termination codons in the SOIV PB1-F2 originate as silent mutations to valine or leucine $(\mathrm{VL})$ codons of the main PB1 ORF, but whereas VL codons are evenly distributed throughout the PB1 protein, the termination mutations in the +1 frame are not; three of the eleven VL codons have mutated in the PB1-F2 region, which is 90 codons long, but only in two of the 82 VL codons in the remaining 665 codons have mutated. It seems that the peculiarities of the S-OIV PB1-F2 gene, the human-like signature sites and its selectively super- imposed termination codons, probably reflect the outcome of selection rather than being of "little or no evolutionary significance".

Finally, we examined the NS1 protein, which in c. $80 \%$ of over 3000 sequences obtained from Genbank (July 2009) were full length, and at the C-terminus had an intact 'ESEV' motif or a similar sequence, which has been linked with virulence [44]. 7\% of the NS1s were, like that of SOIV, only 219 amino acids long and terminating in '-QK'; most of them $(66 \%)$ had come from pig isolates, $20 \%$ from human, $8 \%$ birds, $5 \%$ horses and fewer than $1 \%$ from mink and dogs, but none were as short as the NS1 protein experimentally truncated to 126 amino acids to attenuate the virus for use in a live vaccine [45].

Thus our examination of sequence signatures and motifs in the S-OIV genome has not clarified our knowledge of its origins, but has certainly raised many new questions.

\section{Conclusion}

Influenza virus is a very significant zoonotic pathogen. Public confidence in influenza research, and the agribusinesses that are based on influenza's many hosts, has been eroded by several recent events. Measures that might restore confidence include establishing both a unified international administrative framework coordinating all surveillance, research and commercial work with this virus, and also a detailed registry of all influenza isolates held for research and vaccine production.

The phylogenetic information presently available does not identify the source of S-OIV, however it provides some clues, which can be translated into hypotheses of where and how it might have originated. Two contrasting possibilities have been described and discussed in this commentary, but more data are needed to distinguish between them. It would be especially valuable to have gene sequences of isolates filling the time and phylogenetic gap between those of S-OIV and those closest to it. We believe that these important sequences are most likely to be found in isolates from as-yet-unsampled pig populations or as-yet-unsampled laboratories, especially those holding isolates of all three clusters of viruses closest to those of S-OIV, and involved in vaccine research and production. Quarantine and trade records of live pigs entering North America could probably focus the search for the unsampled pig population. It is likely that further information about S-OIV's immediate ancestry will be obtained when the unusual features of its PB1-F2 gene are understood.

\section{Abbreviations}

BLAST: Basic Local Alignment Search Tool; ORF: open reading frame. 


\section{Competing interests}

The work reported here was unfunded, and the authors have no competing financial or intellectual property interests.

\section{Authors' contributions}

The work was planned as a result of discussions and projects involving all the authors. Analyses were done by AJG, all authors contributed to the manuscript.

\section{Additional material}

\section{Additional file 1}

Taxonomic methods and sequence Accession Codes. Details of the methods used to produce Figs 2, 3 and 4 together with a listing of the Accession Codes of all the sequences used in the analyses.

Click here for file

[http://www.biomedcentral.com/content/supplementary/1743422X-6-207-S1.DOC]

\section{Acknowledgements}

We thank the two anonymous reviewers for their comments, and also many colleagues, especially Gillian Air, Richard Carter, Joe Dudley, Bill Gallaher, Mark Gibbs, Simon Ho, John Mackenzie, John Maindonald, Matt Phillips and John Trueman, for very helpful comments and suggestions during the protracted gestation of this paper.

\section{References}

I. Dawood FS, Jain S, Finelli L, Shaw MW, Lindstrom S, Garten RJ, Gubareva LV, Xu X, Bridges CB, Uyeki TM: Emergence of a novel swine-origin influenza A (HINI) virus in humans. New England Journal of Medicine 2009, 36 I:

2. Cohen J: Straight from the pig's mouth: swine research with swine influenzas. Science 2009, 325:|40-|4|.

3. Hensley SE, Yewdell JW: Que sera, sera: evolution of the swine HINI influenza A virus. Expert Review of Anti-infective Therapy 2009, 7:763-768

4. Chen J-M, Sun Y-X, Chen J-W, Liu S, Yu J-M, Shen C-J, Sun X-D, Peng D: Panorama phylogenetic diversity and distribution of type A influenza viruses based on their six internal gene sequences. Virology Journal 2009, 6:137.

5. Liu S, Ji K, Chen J, Tai D, Jiang W, Hou G, Chen J, Li J, Huang B: Panorama phylogenetic diversity and distribution of type $A$ influenza Virus. PLoS ONE 2009, 4:e5022

6. Babakir-Mina M, Dimonte S, Perno CF, Ciotti M: Origin of the 2009 Mexico influenza virus: a comparative phylogenetic analysis of the principal external antigens and matrix protein. Archives of Virology.

7. Garten RJ, Davis CT, Russell CA, Shu B, Lindstrom S, Balish A, Sessions WM, Xu X, Skepner E, Deyde V, et al.: Antigenic and genetic characteristics of swine-origin 2009 A(HINI) influenza viruses circulating in humans. Science 2009, 325:197-201.

8. Smith GJD, Vijaykrishna D, Bahl J, Lycett SJ, Worobey M, Pybus OG, Ma SK, Cheung CL, Raghwani J, Bhatt $S$, et al.: Origins and evolutionary genomics of the 2009 swine-origin HINI influenza A epidemic. Nature 2009.

9. Nava GM, Attene-Ramos MS, Ang JK, Escorcia M: Origins of the new influenza $A(H I N I)$ virus: time to take action. Eurosurveillance 2009, I 4: I-22.

10. Solovyov A, Palacios G, Briese T, Lipkin WI, Rabadan R: Cluster analysis of the origins of the new influenza $A(H I N I)$ virus. Eurosurveillance 2009, | 4: |-55.
II. Fraser C, Donnelly CA, Cauchemez S, Hanage WP, Van Kerkhove MD, Hollingsworth DT, Griffin J, Baggaley RF, Jenkins HE, Lyons EJ, et al: Pandemic potential of a strain of influenza $A$ (HINI): early findings. ScienceExpress 2009.

12. Brockwell-Staats C, Webster RG, Webby RJ: Diversity of influenza viruses in swine and the emergence of a novel human pandemic influenza A (HINI). Influenza and Other Respiratory Viruses 2009, 3:207-213.

13. Shinde V, Bridges CB, Uyeki TM, Shu B, Balish A, Xu X, Lindstrom S, Gubareva LV, Deyde V, Garten RJ, et al.: Triple-reassortant swine influenza A (HI) in humans in the United States, 2005-2009. New England Journal of Medicine 2009, 36 I:

14. Olsen CW: The emergence of novel swine influenza viruses in North America. Virus Research 2002, 85:199-210.

I5. Richt JA, Lager KM, Janke BH, Woods RD, Webster RG, Webby RJ: Pathogenic and antigenic properties of phylogenetically distinct reassortant $\mathrm{H} 3 \mathrm{~N} 2$ swine influenza viruses cocirculating in the United States. Journal of Clinical Microbiology 2003, 41:3198-3205.

16. Pensaert M, Ottis K, Vanderputte J, Kaplan MM, Buchmann PA: Evidence for the natural transmission of influenza $A$ virus from wild ducks to swine and its potential for man. Bulletin of the World Health Organisation 198I, 59:75-78.

17. Brown IH, Ludwig S, Olsen CW, Hannoun C, Scholtissek C, Hinshaw VS, Harris PA, McCauley JW, Strong I, Alexander DJ: Antigenic and genetic analyses of HINI influenza $A$ viruses from European pigs. Journal of General Virology 1997, 78:553-562.

18. Scholtissek C, Burger H, Bachmann PA, Hannoun C: Genetic relatedness of hemagglutinins of the $\mathrm{HI}$ subtype of influenza $A$ viruses isolated from swine and birds. Virology 1983, 1 29:521-523.

19. Webster RG, Bean WJ, Gorman OT, Chambers TM, Kawaoka Y: Evolution and ecology of influenza $\mathbf{A}$ viruses. Microbiological Reviews 1992, 56:152-179.

20. Pascua PNQ, Songa M-S, Lee JH, Choi H-W, Han JH, Kim J-H, Yoo GJ, Kim C-J, Choi Y-K: Seroprevalence and genetic evolutions of swine influenza viruses under vaccination pressure in Korean swine herds. Virus Research 2008, I 38:43-49.

21. Yu H, Hua R-H, Zhang Q, Liu T-Q, Liu H-L, Li G-X, Tong G-Z: Genetic evolution of swine influenza $A$ (H3N2) viruses in China from 1970 to 2006. Journal of Clinical Microbiology 2008, 46: $1067-1075$.

22. Kingsford C, Nagarajan N, Salzberg SL: 2009 Swine-Origin Influenza A (HINI) resembles previous influenza isolates. PLoS ONE 2009, 4:e6402.

23. Fourment M, Gibbs AJ, Gibbs MJ: SWeBLAST: A Sliding Window Web-based BLAST Tool for recombinant analysis. Journal of Virological Methods 2008, I 52:98-101.

24. Fourment M, Gibbs MJ: PATRISTIC: a program for calculating patristic distances and graphically comparing the components of genetic change. BMC Evolutionary Biology 2006, 6:I.

25. Trifonov V, Khiabanian H, Rabadan R: Geographic pependence, surveillance, and origins of the 2009 influenza A (HINI) virus. New England Journal of Medicine 2009, 36 I : I I5-I I9.

26. Trifonov $\mathrm{V}$, Racaniello $\mathrm{V}$, Rabadan $\mathrm{R}$ : The contribution of the PBI-F2 protein to the fitness of influenza $A$ viruses and its recent evolution in the 2009 influenza $A$ (HINI) pandemic virus. PLoS Currents: Influenza 2009, 22:

27. Tobita K, Tanaka T, Hayase $Y$ : Spontaneous excretion of virus from MDCK cells persistently infected with influenza virus A/PR/8/34. Journal of General Virology 1997, 78:563-566.

28. Stang A, Petrasch-Parwez E, Brandt S, Dermietzel R, Meyer HE, Stühler K, Liffers S-T, Überla K, Grunwald T: Unintended spread of a biosafety level 2 recombinant retrovirus. Retrovirology 2009 , 6:68.

29. Mackenzie D: Swine flu: the predictable pandemic? New Scientist 2009, 2706:6-7.

30. Gallaher WR: Towards a sane and rational approach to management of influenza HIHI 2009. Virology Journal 2009, 6:5I

31. Anonymous: American Association of Veterinary Virologists 2009 [http:// www.aasp.org/public/HIN I InfluenzaVeterinaryTalkingPoints-05-0509.doc].

32. Bush RM, Fitch WM, Bender CA, Cox NJ: Positive selection on the $\mathrm{H3}$ hemagglutinin gene of human influenza virus $A$. Molecular Biology and Evolution 1999, I6:|457-|465. 
33. Bush RM, Smith CB, Cox NJ, Fitch WM: Effects of passage history and sampling bias on phylogenetic reconstruction of human influenza A evolution. Proceedings of the National Academy of Sciences, USA 2000, 97:6974-6980.

34. Cohen J: Interview with head of Mexico's top swine flu lab. Sciencelnsider 2009 [http://blogs.sciencemag.org/scienceinsider/2009/05/ exclusive-inter.html].

35. Robertson JS: Clinical influenza virus and the embryonated hen's egg. Reviews in Medical Virology 1993, 3:97-106.

36. Widjaja L, llyushina N, Webster RG, Webby RJ: Molecular changes associated with adaptation of human influenza $A$ virus in embryonated chicken eggs. Virology 2006, 350:137-145.

37. Subbarao EK, London W, Murphy BR: A single amino acid in the PB2 gene of influenza $A$ virus is a determinant of host range. Journal of Virology 1993, 67: 176I-1764.

38. Chen GW, Chang SC, Mok CK, Lo YL, Kung YN, Huang JH, Shih YH, Wang JY, Chiang C, Chen C], Shih SR: Genomic signatures of human versus avian influenza $A$ viruses. Emerging Infectious Diseases 2006, I 2:1353-1360.

39. Wise HM, Foeglein A, Sun J, Dalton RM, Patel S, Howard W, Anderson EC, Barclay WS, Digard P: A complicated message: identification of a novel PBI-related protein translated from influenza A virus segment 2 mRNA. Journal of Virology 2009, 83:802I-803I.

40. McAuley JL, Hornung F, Boyd KL, Smith AM, McKeon R, Bennink J, Yewdell JW, McCullers JA: Expression of the 1918 influenza $A$ virus $P B I-F 2$ enhances the pathogenesis of viral and secondary bacterial pneumonia. Cell Host and Microbe 2007, 2:240-249.

41. Conenello GM, Palese P: Influenza A virus PB I-F2: a small protein with a big punch. Cell Host and Microbe 2007, 2:207-209.

42. Conenello GM, Zamarin D, Perrone LA, Tumpey T, Palese P: A single mutation in the PBI-F2 of H5NI (HK/97) and 1918 influenza A viruses contributes to increased virulence. PLOS Pathogens 2007, 3:el4I.

43. Zamarin $D$, Ortigoza MB, Palese $P$ : Influenza A virus PB I-F2 protein contributes to viral pathogenesis in mice. Journal of Virology 2006, 80:7976-7983.

44. Krug RM, Yuan W, Noah DL, AG L: Intracellular warfare between human influenza viruses and human cells: the roles of the viral NSI protein. Virology 2003, 309:181-189.

45. Richt JA, Lekcharoensuk $P$, Lager KM, Vincent $A L$, Loiacono $C M$, Janke BH, Wu W-H, Yoon K-J, Webby RJ, Solórzano A, García-Sastre $A$ : Vaccination of pigs against swine influenza viruses by using an NSI-truncated modified live-virus vaccine. Journal of Virology 2006, 80: | 1009-11018.

Publish with Bio Med Central and every scientist can read your work free of charge

"BioMed Central will be the most significant development for disseminating the results of biomedical research in our lifetime. "

Sir Paul Nurse, Cancer Research UK

Your research papers will be:

- available free of charge to the entire biomedical community

- peer reviewed and published immediately upon acceptance

- cited in PubMed and archived on PubMed Central

- yours - you keep the copyright
BioMedcentral 